Review Article

\title{
Chronic Pain in Inflammatory Arthritis: Mechanisms, Metrology, and Emerging Targets-A Focus on the JAK-STAT Pathway
}

\author{
Fausto Salaffi, ${ }^{1}$ Giovanni Giacobazzi, ${ }^{2}$ and Marco Di Carlo $\mathbb{D}^{1}$ \\ ${ }^{1}$ Rheumatology Department, Università Politecnica delle Marche, Jesi, Ancona, Italy \\ ${ }^{2}$ Medical Department, Pfizer, Rome, Italy \\ Correspondence should be addressed to Marco Di Carlo; dica.marco@yahoo.it
}

Received 7 September 2017; Accepted 13 December 2017; Published 7 February 2018

Academic Editor: Jacob Ablin

Copyright (c) 2018 Fausto Salaffi et al. This is an open access article distributed under the Creative Commons Attribution License, which permits unrestricted use, distribution, and reproduction in any medium, provided the original work is properly cited.

\begin{abstract}
Chronic pain is nowadays considered not only the mainstay symptom of rheumatic diseases but also "a disease itself." Pain is a multidimensional phenomenon, and in inflammatory arthritis, it derives from multiple mechanisms, involving both synovitis (release of a great number of cytokines) and peripheral and central pain-processing mechanisms (sensitization). In the last years, the JAK-STAT pathway has been recognized as a pivotal component both in the inflammatory process and in pain amplification in the central nervous system. This paper provides a summary on pain in inflammatory arthritis, from pathogenesis to clinimetric instruments and treatment, with a focus on the JAK-STAT pathway.
\end{abstract}

\section{Introduction}

Chronic pain is not only a critical symptom of rheumatic diseases but also has rather been defined as "a disease itself" and has wide biopsychosocial implications [1]. Pain in arthritis recognizes different mechanisms, including inflammation of the articular and periarticular structures, and both peripheral and central mechanisms are involved. With the disease progression, pain can derive from structural changes within the joint. These different aspects make difficult to correctly diagnose the type of pain and to treat it appropriately. Beyond the well-established analgesic therapies, new targets emerged over the last decade in the therapeutic approach to the multifactorial pain associated with inflammatory arthritis, such as the Janus kinase/signal transducer and activator of the transcription (JAK-STAT) pathway. This paper is an overview of the pathogenic mechanisms of pain in inflammatory arthritis, with a focus on the JAK-STAT signalling pathway. It attempts also to provide guidance on how to measure the impact of pain in rheumatic diseases and to treat it with old and new treatment approaches.

\section{Neuroinflammatory Mechanisms of Pain}

Pain is a multidimensional phenomenon, defined by the International Association for the Study of Pain (IASP) as "an unpleasant sensory and emotional experience associated with actual or potential tissue damage, or described in terms of such damage" [2]. Nociception is composed physiologically of four processes: transduction, transmission, modulation, and perception, in which transmission goes through sensory neurons, called nociceptors, which have high activation thresholds. Four main groups of pain are recognized, based on etiology: inflammatory, cancer, neuropathic, and central pain [3].

The nervous system communicates with the immune system [4], and inflammation at the site of the affected nerve is the common underlying mechanism between neuropathic and inflammatory pain. The central nervous system (CNS) elements involved in both development and maintenance of neuropathic pain are the microglia and the astrocytes. Mediators of neuropathic pain are cytokines and neurotrophic factors that are capable of activating neurons directly or via glial cells. To date, many substances have been 
identified as mediators of the neuropathic pain pathways. Moreover, both astrocytes and microglia can release proinflammatory cytokines able to activate glia and neurons expressing receptors for these molecules.

As recently reviewed by Busch-Dienstfertig and Gonzàlez-Rodrìguez [3], during the inflammatory process, an innate immune cascade occurs, yielding release of active factors from the blood and local and migrating inflammatory cells. Both pro- and anti-inflammatory cytokines are released. Among proinflammatory ones, tumor necrosis factor- (TNF-) $\alpha$ and interleukin- (IL-) 1 can directly sensitize nociceptive fibers and can activate different pathways, which in turn leads to the accumulation of more proinflammatory cytokines, that activate prostaglandin synthesis. TNF- $\alpha$ is synthesized by microglia, astrocytes, and some populations of neurons. TNF- $\alpha$ has several important functions in the CNS, including injury-mediated microglial and astrocyte activation, regulation of blood-brain barrier permeability, febrile responses, glutamatergic transmission, and synaptic plasticity. The mechanism in which IL- $1 \beta$ induces sensory neuronal sensitization to pain (through IL-1 receptor type-1 activation) is thought to involve tyrosine kinases as well as protein kinase C [5]. The great amount of prostaglandins accumulating in the injured tissue, as a consequence of this cascade, increases neuron sensitivity [6-9]. This "neuroinflammatory" environment activates in turn the glial cells in the brain and spinal cord, giving rise to the process of nociception [10].

Another element of communication between the immune and the nervous systems is the nerve growth factor (NGF), which mediates many of the activities exerted by cytokines as TNF- $\alpha$ and IL- $1 \beta$. In fact, the NGF activates macrophages, inducing the release of multiple factors, including the NGF itself [11]. In summary, the process of pain involves several mechanisms mediated by both inflammatory and neural factors.

On the other hand, some cytokines contribute to antiinflammatory and antinociceptive processes: IL-10 is a powerful anti-inflammatory cytokine, as shown in animal models of chronic pain [12], while IL- $1 \beta$ demonstrated to stimulate the synthesis of opioid receptors in dorsal root ganglia neurons [13]. Moreover, the immune cells present in inflamed tissues also contain opioids [14], whose release is dependent on proinflammatory cytokines, such as IL- $1 \beta$ and IL-6 $[15,16]$. Glial cells can even release anti-inflammatory cytokines.

\section{A Great Amplifier of Chronic Pain and Inflammation: Obesity}

A large volume of evidence points to the concurrence of obesity and pain complaints [17]. Severe obesity in the elderly doubles the likelihood of having chronic pain [18]. Similarly, obesity appears to be a risk factor for developing neuropathic pain [19]. Research suggests that obesity may be characterized by a low-grade chronic inflammatory state as reflected by elevated levels in many inflammatory markers in the serum, such as IL-6 and C-reactive protein (CRP) [20-22]. Macrophage accumulation in adipose tissues has also been demonstrated in obese humans [23] and is known to play an important role in production and release of these inflammatory mediators [24]. Adipocytes, as well as providing an energy store for the body, are involved in the regulation of inflammatory processes and autoimmunity. It is known that adipocytes secrete approximately 50 different adipokines. Among these, the most well known are the following: leptin, visfatin, resistin, chemerin, and adiponectin $[25,26]$. Leptin is considered a proinflammatory adipokine in immune cells and joint cells, although its role in animal models of arthritis remains unclear, with contrasting results [27]. Moreover, leptin exhibits similar structural and functional characteristics to the IL-6 cytokine family and increases inflammation by regulation of Th1-dependent response and production of proinflammatory cytokines by macrophages such as TNF- $\alpha$, IL-6, and IL-12. Visfatin, also called nicotinamide phosphoribosyltransferase (Nampt), is a proinflammatory adipokine in immune and joint cells, and its blockade reduces arthritis severity similar to that of antiTNF drugs. Resistin exists in two forms: as a hexamer or the more bioactive trimer. In rheumatoid arthritis (RA), it is associated with increased inflammation, particularly by the acute-phase reactant IL-1Ra antagonizing IL- $1 \beta$, joint destruction, and glucocorticosteroid utilization [28]. Additionally, resistin may act as a marker of inflammation in other rheumatic disorders such as systemic lupus erythematosus (SLE) and systemic sclerosis (SSc) [29]. Chemerin is another active protein exhibiting two opposite actions. On one hand, it intensifies inflammation and stimulates chemotaxis of dendritic cells, macrophages, and NK cells to inflammation sites. Nevertheless, it inhibits production of inflammatory mediators and proinflammatory cytokines (TNF- $\alpha$ and IL-6) and stimulates adiponectin synthesis. Adiponectin has several isoforms and is involved in the pathogenesis of RA. There are studies indicating the activity of this adipokine in joints. It increases inflammation in joints, has a proinflammatory effect on chondrocytes, and contributes to destruction of the cartilage [30].

\section{The JAK-STAT Pathway in Pain Modulation}

Intracellular pathways are critical to immune cell activation, proinflammatory cytokine production, and cytokine signalling. JAKs are constitutively associated with many cytokine receptors. The binding of cytokines to a receptor associated with JAKs leads to the tyrosine phosphorylation of the receptor and generates a docking site for STATs. The STATs are thus phosphorylated and translocate to the nucleus where they may activate transcription of several genes [31].

In this complex milieu of products and cells, the JAKSTAT pathway is involved in the production of both pronociceptive and anti-inflammatory cytokines [3], playing an important role in the signalling pathway of neuropoietic cytokines and being also linked to the inflammatory response [32]. It has been reported to take on a role in nerve regeneration, in the inflammatory cascade activated by the microglia, and in the reaction of glial cells to CNS damage that leads to gliosis [33-35]. Reactive astrogliosis is a critical 
process for generating activated astrocytes. These cells may result in producing proinflammatory cytokines like TNF- $\alpha$, IL- $1 \beta$, and IL- 6 and thereby in modulating dorsal horn pain processing.

In contrast to TNF- $\alpha$ and IL- $1 \beta$, IL- 6 through its specific receptor gp 80 and the shared gp 130 subunit, mainly activates the JAK-STAT transduction pathway. In addition, IL-6 may also signal via the mitogen-activated protein kinase cascade [36]. IL-6 induces JAK (JAK1 and JAK2) mediated phosphorylation of STAT1 and STAT3 proteins. IL-6 and STAT3 are key mediators of both chronic inflammation and joint destruction in RA [37]. In the CNS, STAT3 plays an essential role in IL-6 signalling. The blockade of the JAK-STAT3 activity prevented the strong expression of IL- 6 and of other factors induced in the spinal cord after nerve lesion in rats and attenuated mechanical allodynia [38].

Another proinflammatory cytokine, IL- $1 \beta$, is involved in the pathogenesis of the neuropathic pain component of RA regulated by the JAK-STAT pathway [39-41]. Inhibition of the JAK-STAT cascade blocks pro-IL- $1 \beta$ expression and IL- $1 \beta$ maturation, resulting in control of neuropathic pain. On the other hand, an anti-inflammatory and antinociceptive cytokine such as IL-4 carries out its effects via JAK-STAT [42-44].

Two other cytokines with predominantly proinflammatory action, namely, IL-12 and IL-18, also contribute to hyperalgesia by elevating the endothelin levels and by enhancing proinflammatory cytokines such as TNF- $\alpha$ [45]. Other molecules, as IL-13 and IL-10, share the JAK-STAT common pathway as a mechanism to exert their antinociceptive effect.

IL-10 has been shown to possess the most potent antiinflammatory action, and its release downregulates the expression of IL- $1 \beta$, IL- 6 , and TNF- $\alpha$. It acts by downregulating proinflammatory genes, which leads to decreased expression of the abovementioned cytokines and their receptors and upregulation of their functional antagonists [46].

JAK-STATs showed to play a further role in maintaining neuropathic pain, by mediating astrocyte proliferation following nerve injury $[47,48]$. To stop the astrocyte proliferative process may thus represent a therapeutic target for neuropathic pain after peripheral nerve injury. Another recent work showed that the microglial activity of the JAKSTAT3 proteins has effects on the functional properties of astrocytes and neurons [49], thus possibly participating in the remodelling of the spinal cord following peripheral nerve injury. Interestingly, the STAT3 signalling is implicated in astrogliogenesis from neural stem cells.

Conversely, the JAK-STAT pathway is of importance in the IL-4-induced upregulation of the opioid system [50-52]; in turn, endogenous and exogenous opioids stimulate IL-4 transcription in T cells $[53,54]$. However, this strict connection between IL-4 and the opioid system is not the primary mechanism of IL-4 antinociceptive function, which is rather due to the inhibition of proinflammatory cytokines and factors $[3,55]$. The relevance of IL- 4 in pain was supported by an investigation of IL-4 deficiency in mice $[56,57]$.

In order to control the magnitude and duration of cytokine signalling, the JAK-STAT pathway is strongly regulated by different endogenous inhibitory mechanisms [36], including receptor internalization by vesicles followed by receptor degradation, posttranslational modifications of STAT proteins, and dephosphorylation by phosphatases (PTPs), as reviewed by Shuai [58].

In spite of this complex pathway and network of mediators, clinical trials with exogenous JAK inhibitors in the treatment of chronic inflammatory arthritis showed a significant positive impact on pain, as detailed below.

\section{Pain in Inflammatory Arthritis}

Patients with inflammatory arthritis commonly report pain as their most important problem, associated with psychological distress and impaired physical and social functioning. Moreover, pain is also a socioeconomic issue since it implies a significant decrease in work productivity and an increase in healthcare resource utilization, with a consequent significant impact on direct and indirect costs of rheumatic diseases $[59,60]$. Pain plays an important role in health-related quality of life (HRQoL) in patients with RA. The Pain Management Task Force of the American College of Rheumatology (ACR) stated that "insufficient efforts were devoted to pain management" [61].

Pain is associated with disease activity [62-65], but it has been observed that although it is a marker of inflammation, its intensity poorly correlates with measures of inflammation $[66,67]$, and intense and disabling pain may persist even when the inflammatory disease is controlled [68]. Nonsteroidal anti-inflammatory drugs (NSAIDs) and biological and nonbiological disease-modifying antirheumatic drugs (DMARDs) are generally effective in relieving inflammatory pain symptoms. However, many patients continue to experience pain due to alterations in central pain regulation mechanisms, developing chronic widespread pain (CWP) $[69,70]$. In this view, it is important to distinguish between inflammatory pain and sensitization in patients with rheumatic diseases, since therapies may be different. Mechanisms of peripheral and central RA pain in humans seem to be similar to those observed in animal models, where they have been widely investigated [71].

\section{Peripheral Pain Mechanisms}

Peripheral pain may be caused by articular alterations occurring during inflammatory joint diseases which can activate or sensitize primary afferent nociceptive neurons. In the RA synovium or synovial fluids, many algogens, cytokines, and chemokines are able to sensitize the peripheral nerves [72-76]. The peripheral sensitization is characterized by high spontaneous activity, a low threshold of activation of the nociceptive fibers, and increased responsiveness with local release of neuropeptides following stimulation [77]. The reiterative nociceptive stimulating action leads to sensitized spinal neurons. In humans with RA and in several animal models of inflammation, neutralization of TNF- $\alpha$ induces a rapid reduction of nociceptive neuronal activity in the afferent neurons. In the synovium and in the synovial fluids from patients with RA, opioids and anti-inflammatory cytokines have also been detected, but their ability to directly moderate arthritic joint pain has not been fully elucidated yet [78-82]. 


\section{Central Pain Processing}

Central pain processing is enhanced in RA [83]. Indeed, the degree of tissue inflammation or of articular damage is not the only predictor of the presence or the severity of pain. Under the category "central pain," any dysfunction or pathologic condition of the CNS contributing to the development or maintenance of chronic pain is included. This concept also incorporates the psychosocial aspects of pain perception [83]. Central pain may also occur concomitantly with other symptoms that are centrally mediated, such as fatigue, insomnia, memory difficulties, and mood disturbances. Increased pain sensitivity regards not only inflamed joints but also remote, nonarticular sites, and reduced thresholds for pressure and thermal pain have also been reported in RA patients $[84,85]$. Repeated painful stimuli seem also to have a role in the alterations of the diffuse noxious inhibitory control (DNIC), described as low functioning in patients with RA [82]. Functional magnetic resonance imaging (MRI) studies showed that patients with central pain states, when exposed to stimuli that are innocuous to healthy subjects, exhibit an increased neuronal activity in the brain regions devoted to pain processing, accounting for such a condition of diffuse hyperalgesia/pain augmentation. These pain-processing regions include the thalamus, the insular cortex (IC), the primary and secondary somatosensory cortex (SI and SII), the posterior cingulate cortex (PCC), and the anterior midcingulate cortex (ACC) [86]. Furthermore, it has been demonstrated that cerebral activity associated with evoked pain in RA is moderated by the psychological state [87]. Augmented pain processing has been associated with low mood, and such an association seems to be due to changes in cortical opioid receptor binding [88].

\section{Psychological Aspects in Pain}

Pain exacerbates psychological distress, and distress in turn can augment pain [71]. Worse mental health and higher levels of depression and anxiety have been reported in RA patients $[86,89,90]$. Depression is demonstrated to be associated with inflammatory disease activity, physical disability, poor treatment outcome, sensitivity to pain and reported pain severity, and even early mortality [91]. Recent findings also highlight that these variables contribute to the overuse of health services. Pain is predictive of depression in RA patients [92], and patients with depression report worse RA [93]. It has been shown that psychological characteristics are better predictors of pain compared to measures of joint inflammation or damage [94]. As in healthy people, in RA patients, factors of acute and chronic psychological distress can enhance central pain processing [91, 95]. Psychological interventions, particularly the cognitive behavioral therapy, or pharmacological treatments can reduce depression and alter central pain processing in people with RA [96, 97]. Furthermore, the prevalence of chronic, noninflammatory pain syndromes such as fibromyalgia (FM) is higher (15-30\% of individuals) among patients suffering from RA than that in the general population $(2 \%)[98,99]$, suggesting that pain and/or stress accompanying chronic rheumatic diseases may trigger a condition such as FM. Patients with inflammatory arthritis and FM are more likely to have a poorer HRQoL than those without FM $[61,100]$, and the presence and severity of FM in RA also influence the response to biologic and traditional DMARDs and predict worse pain and functional prognosis following arthroplasty and back surgery [83].

Figure 1 depicts the actors involved in the supposed mechanisms of pain sensitization in inflammatory arthritis.

\section{How to Measure Chronic Pain?}

Individuals with chronic pain are frequently observed in rheumatological clinical practice, and the appropriate pain assessment may be crucial for successful pain management. As we described in a previous work [101], pain assessment is an interactive process that involves several actors: patients and their families, nurses, physicians, and other health professionals; pain assessment should include adequate diagnostic appraisal, physical evaluation, and a review of the patient's physical environment, of the psychosocial features, and of medical and surgical procedures. In any case, self-reporting scales remain the primary source, facilitating reassessments and follow-up. Different uni- and multidimensional pain measurement scales are available, none of which is suitable for all patients [102-104]. Moreover, novel instruments and healthcare monitoring systems based on information and communication technology have been developed to assess chronic musculoskeletal pain [101].

Some validated scales and questionnaires are commonly used in RA [70], including the Visual Analogue Scale (VAS), the Verbal Rating Scale (VRS), the Numerical Rating Scale (NRS), and the Faces Pain Rating Scale.

When a simple, one-item instrument is not enough to adequately measure pain [102], more comprehensive instruments combining measures of different dimensions of pain are needed [104]. However, these are often long tools with poor patient compliance. The most widely used multidimensional generic pain scales are the McGill Pain Questionnaire (MPQ) and its Short-Form (SF-MPQ), the Brief Pain Inventory (BPI), the Chronic Pain Grade Questionnaire (CPGQ), and the West Haven-Yale Multidimensional Pain Inventory (WHYMPI) [105-108]. A disease-specific scale to evaluate pain in patients with RA is the Rheumatoid Arthritis Pain Scale (RAPS) [109]. The painDETECT questionnaire, developed to measure noninflammatory and neuropathic pain, has been investigated in patients with different musculoskeletal pain conditions, including RA. The questionnaire is structured around nine items, two of which concern the temporal and spatial (radiating) characteristics of the individual pain pattern, and the other seven are weighted on sensory descriptors [110].

However, among unidimensional assessment tools, counting the number of swollen (SJC) and/or tender joints (TJC) remains the most specific quantitative clinical method to evaluate and monitor the status of patients with 


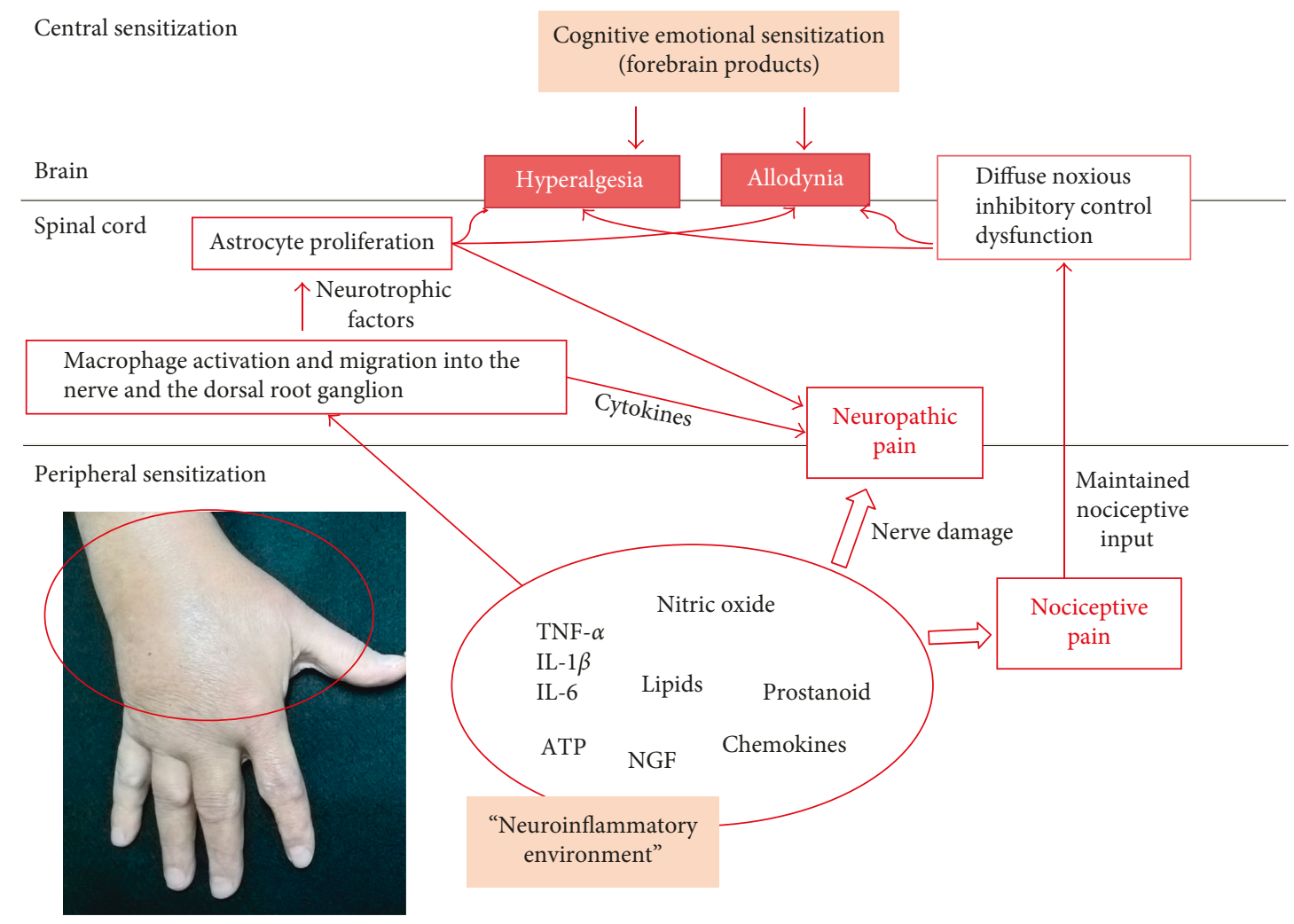

Figure 1: Peripheral and central mechanisms of pain sensitization in inflammatory arthritis. Synovitis can induce the production of molecules responsible for both nociception and neuropathic pain (through the damage of the nerves and the recruitment of macrophages in the nerves themselves and in the dorsal root ganglion). Repeated nociceptive stimuli can modify the function of the diffuse noxious inhibitory control (DNIC), with augmented pain perception as a consequence. Inflammatory cells stimulate, at the level of the central nervous system, the glial cell proliferation. Glial cells in turn provoke neural alterations responsible, at least in part, for hyperalgesia and allodynia. Pain sensitization is also strongly influenced by the psychological baggage.

inflammatory arthritis [111]: namely, the SJC quantifies the inflammation, while the TJC better quantifies the amount of pain. Joint pain may be measured by the "rule of thumb" (i.e., pain at rest induced by a thumb and index pressure that whitens the examiner's nail bed) or by quantifying the pain on motion for the shoulder, tarsal, and hip joints. The number of joints considered can vary from 28 to 80 , with different relative weights.

The domain "pain" is predominant also in assessing HRQoL in patients with RA. It strongly influences the scores of disease-specific scales, such as the Arthritis Impact Measurement Scales (AIMS) and AIMS2 [112, 113], and wellknown generic scales, such as the European Quality of Life-5 Dimensions (EQ-5D) and Medical Outcomes Study (MOS) 36-Item Short-Form Health Survey (SF-36) [114, 115]. Table 1 summarizes the available scales to measure pain in patients with RA.

Disease-specific HRQoL tools are available for the majority of rheumatic diseases, and pain takes on a pivotal role in all of them [116-124]. Many of these instruments are patient-reported outcomes (PROs). PROs are gaining increasing importance in medicine [125]. Of particular interest is the easy applicability of PROs in the remote monitoring of patients through the web-based technologies $[126,127]$.

\section{Effect of Pain on Disease Assessment}

Studies showed that pain has a significant impact on the patient's assessment of RA disease activity. In a study analyzing 7,028 RA patients from the Quantitative Patient Questionnaires in Standard Monitoring of Patients with RA (QUEST-RA) database [128], pain emerged as the single most important determinant of the patient's global assessment of disease activity (PtGA). Another study, in 646 RA patients of an outpatient clinic starting methotrexate treatment, also concluded that pain was the major determinant of PtGA scores [63]. Pain contributes less to the physician's global assessment of disease activity (PhGA) than to PtGA: in the QUEST-RA study, pain was the fourth most important determinant of PhGA, after SJC, erythrocyte sedimentation rate, and TJC [66], while in the outpatient study, pain was second only to SJC among PhGA determinants [63]. In both studies, pain was one of the most significant predictors of discordance between PtGA and PhGA, being crucial in patients' "disease experience," while often underestimated by clinicians. Other cross-sectional studies indicate that the presence of CWP or FM may significantly affect the assessment of disease activity in RA [84, 128-131], especially when subjective measures are used. Collectively, these results suggest that physicians should better assess the impact of pain on their patients but also has to consider the effect of 
TABLE 1: Scales to measure all the aspects of pain in patients with rheumatoid arthritis.

\begin{tabular}{|c|c|c|c|c|c|}
\hline \multicolumn{2}{|c|}{ Pain scales } & \multicolumn{2}{|c|}{ Health-related quality of life scales } & \multirow{2}{*}{$\begin{array}{l}\text { Pain location } \\
\text { scales }\end{array}$} & \multirow[t]{2}{*}{ Site-specific scales } \\
\hline Unidimensional & Multidimensional & Generic & Disease specific & & \\
\hline $\begin{array}{l}\text { Verbal Rating } \\
\text { Scale (VRS) }\end{array}$ & $\begin{array}{c}\text { McGill Pain } \\
\text { Questionnaire (MPQ) }\end{array}$ & $\begin{array}{l}\text { 36-Item Short-Form } \\
\text { Health Survey (SF-36) }\end{array}$ & $\begin{array}{c}\text { Arthritis Impact } \\
\text { Measurement Scales } \\
\text { (AIMS) }\end{array}$ & $\begin{array}{l}\text { Formal Joint } \\
\text { Count }\end{array}$ & $\begin{array}{l}\text { Western Ontario and } \\
\text { McMaster Universities } \\
\text { Osteoarthritis Index } \\
\text { (WOMAC) }\end{array}$ \\
\hline $\begin{array}{l}\text { Visual Analogue } \\
\text { Scale (VAS) }\end{array}$ & $\begin{array}{l}\text { Short-Form MPQ } \\
\text { (SF-MPQ) }\end{array}$ & $\begin{array}{c}\text { European Quality of Life- } \\
5 \text { Dimensions } \\
\text { (EQ-5D) }\end{array}$ & $\begin{array}{c}\text { Arthritis Impact } \\
\text { Measurement Scales } \\
2 \text { (AIMS2) }\end{array}$ & $\begin{array}{l}\text { Regional Pain } \\
\text { Scale (RPS) }\end{array}$ & $\begin{array}{l}\text { Hip Disability and } \\
\text { Osteoarthritis } \\
\text { Outcome Score } \\
\text { (HOOS) }\end{array}$ \\
\hline $\begin{array}{l}\text { Numerical Rating } \\
\text { Scale (NRS) }\end{array}$ & $\begin{array}{l}\text { Brief Pain Inventory } \\
\text { (BPI) }\end{array}$ & $\begin{array}{l}\text { Sickness Impact Profile } \\
\text { (SIP) }\end{array}$ & & & $\begin{array}{l}\text { Disabilities of the Arm, } \\
\text { Shoulder, and Hand } \\
\text { (DASH) Questionnaire }\end{array}$ \\
\hline $\begin{array}{l}\text { Faces Pain Rating } \\
\text { Scale }\end{array}$ & $\begin{array}{c}\text { Chronic Pain Grade } \\
\text { Questionnaire (CPGQ) }\end{array}$ & $\begin{array}{l}\text { Nottingham Health } \\
\text { Profile (NHP) }\end{array}$ & & & \\
\hline $\begin{array}{l}\text { Thermometer } \\
\text { Pain Scale (TPS) }\end{array}$ & $\begin{array}{l}\text { West Haven-Yale } \\
\text { Multidimensional Pain } \\
\text { Inventory (WHYMPI); } \\
\text { Rheumatoid Arthritis } \\
\text { Pain Scale (RAPS) }\end{array}$ & & & & \\
\hline
\end{tabular}

coexisting central pain when using composite disease measures of disease activity in inflammatory arthritis.

\section{Pharmacological Treatment of Pain in Inflammatory Arthritis}

Recommendations for the pharmacologic management of pain in inflammatory arthritis have been recently published by the " $3 e$ (evidence, expertise, and exchange) initiative," involving 17 nations [132]. The authors based their recommendations on Cochrane Database and other systematic reviews [133-138]. The main treatment options include (i) nonsteroidal anti-inflammatory drugs (NSAIDs) and acetaminophen as the first-line therapy, (ii) NSAIDs + acetaminophen or an alternative NSAID second-line therapy, and (iii) weak opioids when NSAIDs and acetaminophen have failed or are contraindicated. Antidepressants may be used as adjuvant therapy, but their analgesic role in inflammatory arthritis is still controversial [139]. The $3 \mathrm{e}$ initiative recommends gabapentin and pregabalin as potential adjuvant treatments that were shown to reduce the release of neurotransmitters in peripheral pain syndromes. The $3 \mathrm{e}$ initiative authors strongly recommend to take into consideration the type of pain and of arthritis, the presence of comorbidities, the addictive potential of the medication, and the patient's preference when choosing the most appropriate pain treatment [132].

A Cochrane systematic review of the existing literature included a majority of studies dated before 1990 [140], and efficacy data beyond six weeks of treatment duration as well as in comorbid patients are scarce [141145]. There is a need for new large and long-term trials, including also patients with comorbidities to optimize the use of analgesics and adjuvant therapy in RA patients. In Table 2 are listed the main Cochrane systematic reviews about pain treatment in patients with inflammatory arthritis.

Traditional DMARDs, such as methotrexate, sulphasalazine, and leflunomide, reduce joint pain while suppressing inflammation over several weeks, maintaining these effects over months, and their rapid introduction is recommended by current guidelines, preferably in combination. Many common DMARDs may have some of their adverse effects potentiated by specific analgesic medications; however, a Cochrane systematic review concluded that NSAIDs in combination with methotrexate are generally safe, though recommending appropriate monitoring and avoidance of ASA [146]. In the presence of active disease and pain that is inadequately controlled by methotrexate, addition of a biologic agent may be useful [147]. Biologic DMARDs include TNF-blocking agents (infliximab, adalimumab, golimumab, certolizumab pegol, and etanercept); rituximab, an antiCD20 B-cell-depleting monoclonal antibody (MoAb); tocilizumab which is a IL-6 receptor-blocking MoAb; the IL-1 receptor antagonist anakinra; and the T-cell activation inhibitor abatacept. Second-generation drugs include the anti-IL-17 MoAbs secukinumab and ixekizumab; brodalumab, a MoAb blocking the IL-17 receptor; selective smallmolecule inhibitors of intracellular signal transduction pathways, such as the JAK pathway (tofacitinib and baricitinib); and the spleen tyrosine kinase (fostamatinib). Biologic agents reduce joint pain in RA by reducing inflammation, decreasing peripheral and central sensitization, and preventing long-term joint damage [70, 71].

A growing interest for the treatment of patients suffering from chronic diseases is directed towards pleiotropic natural products. Many substances, such as omega-3 polyunsaturated fatty acids (n-3 PUFA), curcumin, resveratrol, theanine, theaflavin derivatives, and $\alpha$-lipoic acid, can be incorporated into pharmacotherapies to improve therapy 
TABle 2: Principal Cochrane systematic reviews on pain management in inflammatory arthritis.

\begin{tabular}{ll}
\hline Topics & Main conclusions \\
\hline & (i) Limited evidence that weak oral opioids may be effective analgesics for some patients with \\
Opioids (Whittle et al. [133]) & rheumatoid arthritis, but adverse effects are common and may offset the benefits of this class of \\
& medications. \\
& (ii) Insufficient evidence to conclude regarding the use of weak opioids for longer than six weeks or \\
the role of strong opioids.
\end{tabular}

Neuromodulators (Richards et al. [135])

Antidepressants (Richards et al. [139])

Pain management in rheumatoid arthritis and cardiovascular or renal comorbidity (Marks et al. [141])

Pain management in inflammatory arthritis and gastrointestinal or liver comorbidity (Radner et al. [142])

Combination therapy for pain management in inflammatory arthritis (Ramiro et al. [140]) (i) Weak evidence that oral nefopam, topical capsaicin, and oromucosal cannabis are all superior to placebo in reducing pain in rheumatoid arthritis patients.

(ii) Capsaicin could be considered as an add-on therapy for patients with persistent local pain and inadequate response or intolerance to other treatments.

(i) Insufficient evidence to support the routine prescription of antidepressants as pain modulators in rheumatoid arthritis patients since no reliable conclusions about their efficacy can be gathered from eight placebo randomized controlled trials.

(i) Absence of specific evidence in rheumatoid arthritis.

(ii) Guidelines recommend that nonsteroidal anti-inflammatory drugs should be used with caution in the general rheumatoid arthritis population, with the need of extra vigilance in patients with established cardiovascular disease or risk factors.

(iii) Guidelines regarding the use of nonsteroidal anti-inflammatory drugs and opioids in moderateto-severe renal impairment should also be applied to the rheumatoid arthritis population.

(i) Scarce evidence to guide clinicians about how gastrointestinal or liver comorbidities should influence the choice of pain therapy.

(ii) Nonsteroidal anti-inflammatory drugs should be used cautiously in patients with inflammatory arthritis and a history of gastrointestinal comorbidity since the evidence that they may be at increased risk is consistent.

(i) Insufficient evidence to agree upon the value of combination therapy over monotherapy.

(ii) No studies have addressed the value of combination therapy for patients with inflammatory arthritis having persistent pain despite optimal inflammation control. outcomes. These compounds, when combined with pharmaceutical drugs, showed improved efficacy and safety in preclinical and clinical studies of neuropathic pain.

Curcumin, in particular, the primary active ingredient of turmeric (Curcuma longa), has been demonstrated to possess anti-inflammatory, antiosteoclastogenic potential, and antiarthritic properties [148-150]. Treatment with curcumin seems to lessen mechanical allodynia and thermal hyperalgesia through downregulation of TNF- $\alpha$ and TNF- $\alpha$ receptor 1 expression [151]. On the rat model of neuropathic pain, curcumin can markedly alleviate nerve injury-induced neuropathic pain. This analgesic effect may be attributed to the inhibition of astrocyte hypertrophy in the spinal dorsal horn and phosphorylation of the ERK signalling pathway [152]. Moreover, curcumin can inhibit the secretion of TNF- $\alpha$, IL- $1 \alpha$ IL- 6 , and nitric oxide, which can further promote the activation of astrocytes.

\section{Effect of JAK Inhibitors on RA Pain}

Many of the key cytokines use the JAK-STAT pathway to exert their effects rendering them amenable to therapeutic blockade with JAK inhibitors. Given the apparent pathogenic role of a variety of cytokines like IL-6, IL-12, IL-23, interferons, and GM-CSF in RA and other autoimmune diseases, the ability of JAK inhibitors to block such cytokines is likely a major aspect of their mechanism of action. Next to the already existing tofacitinib and baricitinib, a number of other JAK inhibitors are currently in development for the management of RA, with differing in vitro specificities towards the various members of the JAK family. Mechanistically, tofacitinib blocks common cytokines including IL-2, IL-4, IL-7, IL-9, IL-15, and IL-21, all of which are signals through JAK3. In addition, it blocks JAK1, which would result in inhibition of the gp130 family including IL- 6 and IL-11 as well as type II cytokine receptor family such as IFN- $\alpha / \beta$, IFN- $\gamma$, and IL-10 [153]. Tofacitinib is so far the most extensively studied JAK inhibitor, and its effect on the clinical and laboratory measures of RA (ACR20, ACR50, ACR70, DAS28, etc.) is well documented in reviews and meta-analyses [154-161]. Its impact on PROs is also provided in almost all published efficacy studies or reported in specific publications [162-164] and has been recently reviewed by Boyce and colleagues [165]. The results show a significant 
reduction in RA patients' assessment of pain with tofacitinib compared to placebo. Some patients report pain relief within the first 24 hours of JAK inhibitor administration, well before a demonstrable effect on inflammation [164]. Data on the patients' assessment of pain and/or PtGA of the disease are available from further seven clinical studies [166-172]. Tofacitinib, administered $5 \mathrm{mg}$ bid, was associated with a $45 \%-54 \%$ improvement in the patients' assessment of pain and a 44\%-60\% improvement in PtGA, while placebo resulted in less improvement (29\% for pain and 39\% for PtGA) [165]. Overall, it can be concluded that patients' assessment of pain and disease demonstrate that tofacitinib is more effective than placebo.

Baricitinib blocks JAK1 and JAK2 in a highly selective way, interrupting the pathways of several cytokines considered important in RA pathogenesis [173]. In the phase III RA-BUILD clinical trial, baricitinib was associated with clinical improvement and inhibition of progression of radiographic joint damage in patients with RA and an inadequate response or intolerance to conventional synthetic DMARDs [174]. In the phase III RA-BEACON study in RA patients, baricitinib $4 \mathrm{mg}$ significantly improved pain and other PROs over 24 weeks [172].

\section{Conclusions}

We are acutely aware that pain is a major component of many rheumatic diseases, arising from physiological interactions involving the peripheral and central nervous systems. Peripheral signalling, in the form of nociceptive inputs, such as peripheral structural damage and/or inflammation, is mainly implicated in acute pain, whereas inputs from the CNS are responsible for chronic pain. The origin of CWP in patients with arthritis is complex, involving genetic and/or familial predisposition and psychological factors. It is worth underlining that, from the patient's perspective, pain in inflammatory arthritis is reported as the most important problem, significantly affecting HRQoL and working ability. Furthermore, from the clinicians' perspective, pain impacts on disease assessment and treatment choices. Pain has been demonstrated to be the major determinant in PtGA but not in PhGA $[63,66]$. Therefore, we strongly recommend, for effective care of RA, to pay greater attention to the "disease experience" of patients, particularly pain, and to perform accurate pain measurement.

A range of pharmacological analgesics, immunomodulatory agents, serotonin-norepinephrine reuptake inhibitors, and physical and psychological interventions are available to help relieve pain in rheumatic patients. The role of the JAKSTATs in the modulation of both inflammatory and neuropathic pain drew attention to the possible effect of JAK inhibitors, specifically on RA-associated pain. The results are promising, but more experimental and clinical studies and trials of longer duration are required to elucidate the possible role of these molecules in the modulation of pain, as well as in the overall relief of RA burden. Pain-relieving drugs have different mechanisms of action, and we hope that it will be possible, in the next future, to target specific drugs for individual patients in order to improve the outcome for patients with chronic pain.

\section{Disclosure}

Fausto Salaffi received an honorarium from Pfizer in connection with the development of this manuscript. Giovanni Giacobazzi is a Pfizer employee. Marco Di Carlo did not receive an honorarium from Pfizer in connection with the development of this manuscript. Pfizer markets tofacitinib citrate $5 \mathrm{mg}$ for rheumatoid arthritis treatment, as well as celecoxib.

\section{Conflicts of Interest}

The authors declare that they have no conflicts of interest.

\section{Acknowledgments}

Medical writing support was provided by Renata Perego at $\mathrm{CDM}$, and this work was funded by Pfizer.

\section{References}

[1] F. Atzeni, M. Cazzola, M. Benucci, M. Di Franco, F. Salaffi, and P. Sarzi-Puttini, "Chronic widespread pain in the spectrum of rheumatological diseases," Best Practice \& Research Clinical Rheumatology, vol. 25, no. 2, pp. 165-171, 2011.

[2] H. Merskey and N. Bogduk, Classification of Chronic Pain, IASP Publications, Seattle, WA, USA, 1994.

[3] M. Busch-Dienstfertig and S. Gonzàlez-Rodrìguez, "IL-4, JAK-STAT signaling, and pain," JAK-STAT, vol. 2, no. 4, p. e27638, 2013

[4] B. Safieh-Garabedian, S. Poole, J. J. Haddad, C. A. Massaad, S. J. Jabbur, and N. E. Saade, "The role of the sympathetic efferents in endotoxin-induced localized inflammatory hyperalgesia and cytokine upregulation," Neuropharmacology, vol. 42 , no. 6 , pp. 864-872, 2002.

[5] J. Mika, "Modulation of microglia can attenuate neuropathic pain symptoms and enhance morphine effectiveness," Pharmacology Reports, vol. 60, no. 3, pp. 297-307, 2008.

[6] J. M. Zhang and J. An, "Cytokines, inflammation, and pain," International Anesthesiology Clinics, vol. 45, no. 2, pp. 27-37, 2007.

[7] R. J. Miller, H. Jung, S. K. Bhangoo, and F. A. White, "Cytokine and chemokine regulation of sensory neuron function," Handbook of Experimental Pharmacology, vol. 194, pp. 417-449, 2009.

[8] H. Obata, J. C. Eisenach, H. Hussain, T. Bynum, and M. Vincler, "Spinal glial activation contributes to postoperative mechanical hypersensitivity in the rat," Journal of Pain, vol. 7, no. 11, pp. 816-822, 2006.

[9] F. Q. Cunha and S. H. Ferreira, "Peripheral hyperalgesic cytokines," Advances in Experimental Medicine and Biology, vol. 521, pp. 22-39, 2003.

[10] R. Vallejo, D. M. Tilley, L. Vogel, and R. Benyamin, "The role of glia and the immune system in the development and maintenance of neuropathic pain," Pain Practice, vol. 10, no. 3, pp. 167-184, 2010.

[11] C. M. B. de Oliveira, R. K. Sakata, A. M. Issy, L. R. Gerola, and R. Salomão, "Cytokines and pain," Revista Brasileira de Anestesiologia, vol. 61, no. 2, pp. 255-259, 2011.

[12] E. D. Milligan, K. R. Penzkover, R. G. Soderquist, and M. J. Mahoney, "Spinal interleukin-10 therapy to treat peripheral neuropathic pain," Neuromodulation, vol. 15, no. 6, pp. 520-526, 2012. 
[13] C. Stein and C. Zollner, "Opioids and sensory nerves," Handbook of Experimental Pharmacology, vol. 194, pp. 495-518, 2009.

[14] H. L. Rittner, A. Brack, and C. Stein, "The other side of the medal: how chemokines promote analgesia," Neuroscience Letters, vol. 437, no. 3, pp. 203-208, 2008.

[15] P. J. Cabot, L. Carter, C. Gaiddon et al., "Immune cellderived beta-endorphin. Production, release, and control of inflammatory pain in rats," Journal of Clinical Investigation, vol. 100, no. 1, pp. 142-148, 1997.

[16] H. L. Rittner, H. Machelska, and C. Stein, "Leukocytes in the regulation of pain and analgesia," Journal of Leukocyte Biology, vol. 78, no. 6, pp. 1215-1222, 2005.

[17] A. Okifuji and B. Hare, "The association between chronic pain and obesity," Journal of Pain Research, vol. 8, pp. 399-408, 2015.

[18] L. H. McCarthy, M. E. Bigal, M. Katz, C. Derby, and R. B. Lipton, "Chronic pain and obesity in elderly people: results from the Einstein aging study," Journal of American Geriatrics Sociecty, vol. 57, no. 1, pp. 115-119, 2009.

[19] G. Miscio, G. Guastamacchia, A. Brunani, L. Priano, S. Baudo, and A. Mauro, "Obesity and peripheral neuropathy risk: a dangerous liaison," Journal of the Peripheral Nervous System, vol. 10, no. 4, pp. 354-358, 2005.

[20] M. Bluher, M. Fasshauer, A. Tonjes, J. Kratzsch, M. R. Schon, and R. Paschke, "Association of interleukin-6, C-reactive protein, interleukin-10 and adiponectin plasma concentrations with measures of obesity, insulin sensitivity and glucose metabolism," Experimental and Clinical Endocrinology \& Diabetes, vol. 113, no. 9, pp. 534-537, 2005.

[21] U. N. Das, "Is obesity an inflammatory condition?," Nutrition, vol. 17, no. 11-12, pp. 953-966, 2001.

[22] A. Okifuji, G. W. Donaldson, L. Barck, and P. G. Fine, "Relationship between fibromyalgia and obesity in pain, function, mood, and sleep," Journal of Pain, vol. 11, no. 12, pp. 1329-1337, 2010.

[23] S. P. Weisberg, D. McCann, M. Desai, M. Rosenbaum, R. L. Leibel, and A. W. Ferrante Jr., "Obesity is associated with macrophage accumulation in adipose tissue," Journal of Clinical Investigations, vol. 112, no. 12, pp. 1796-1808, 2003.

[24] K. E. Wellen and G. S. Hotamisligil, "Obesity-induced inflammatory changes in adipose tissue," Journal of Clinical Investigations, vol. 112, no. 12, pp. 1785-1788, 2003.

[25] D. B. Panagiotakos, C. Pitsavos, M. Yannakoulia, C. Chrysohoou, and C. Stefanadis, "The implication of obesity and central fat on markers of chronic inflammation: the ATTICA study," Atherosclerosis, vol. 183, no. 2, pp. 308-315, 2005.

[26] L. J. Sandell, "Obesity and osteoarthritis: is leptin the link?," Arthritis and Rheumatism, vol. 60, no. 10, pp. 2858-2860, 2009.

[27] N. Busso, A. So, V. Chobaz-Péclat et al., "Leptin signaling deficiency impairs humoral and cellular immune responses and attenuates experimental arthritis," Journal of Immunology, vol. 168, no. 2, pp. 875-882, 2002.

[28] H. Forsblad d'Elia, R. Pullerits, H. Carlsten, and M. Bokarewa, "Resistin in serum is associated with higher levels of IL-1Ra in post-menopausal women with rheumatoid arthritis," Rheumatology, vol. 47, no. 7, pp. 1082-1087, 2008.

[29] K. Sawicka and D. Krasowska, "Adipokines in connective tissue diseases," Clinical and Experimental Rheumatology, vol. 34, no. 6, pp. 1101-1112, 2016.

[30] K. W. Frommer, A. Schäffler, C. Büchler et al., "Adiponectin isoforms: a potential therapeutic target in rheumatoid arthritis?," Annals of the Rheumatic Diseases, vol. 71, no. 10, pp. 1724-1732, 2012.
[31] P. Dell'Albani, R. Santangelo, L. Torrisi, V. G. Nicoletti, and A. M. G. Stella, "Role of the JAK/STAT signal transduction pathway in the regulation of gene expression in CNS," Neurochemical Research, vol. 28, no. 1, pp. 53-64, 2003.

[32] S. Bauer, B. J. Kerr, and P. H. Patterson, "The neuropoietic cytokine family in development, plasticity, disease and injury," Nature Reviews Neuroscience, vol. 8, no. 3, pp. 221-232, 2007.

[33] F. M. Bareyre, N. Garzorz, C. Lang, T. Misgeld, H. Buning, and $\mathrm{M}$. Kerschensteiner, "In vivo imaging reveals a phasespecific role of STAT3 during central and peripheral nervous system axon regeneration," Proceedings of the National Academy of Sciences, vol. 108, no. 15, pp. 6282-6287, 2011.

[34] J. E. Herrmann, T. Imura, B. Song et al., "STAT3 is a critical regulator of astrogliosis and scar formation after spinal cord injury," Journal of Neuroscience, vol. 28, no. 28, pp. 7231-7243, 2008.

[35] O. S. Kim, E. J. Park, E. H. Joe, and I. Jou, "JAK-STAT signalling mediates gangliosides-induced inflammatory responses in brain microglial cells," Journal of Biological Chemistry, vol. 277, no. 43, pp. 40594-40601, 2002.

[36] H. Kiu and S. E. Nicholson, "Biology and significance of the JAK/STAT signalling pathways," Growth Factors, vol. 30, no. 2, pp. 88-106, 2012.

[37] T. Mori, T. Miyamoto, H. Yoshida et al., "IL- $1 \beta$ and TNF $\alpha$ initiated IL-6-STAT3 pathway is critical in mediating inflammatory cytokines and RANKL expression in inflammatory arthritis," International Immunology, vol. 23, no. 11, pp. 701712, 2011.

[38] E. Dominguez, A. Mauborgne, J. Mallet, M. Desclaux, and M. Pohl, "SOCS3-mediated blockade of JAK/STAT3 signaling pathway reveals its major contribution to spinal cord neuroinflammation and mechanical allodynia after peripheral nerve injury," Journal of Neuroscience, vol. 30, no. 16, pp. 5754-5766, 2010.

[39] M. A. Thacker, A. K. Clark, F. Marchand, and S. B. McMahon, "Pathophysiology of peripheral neuropathic pain: immune cells and molecules," Anesthesia \& Analgesia, vol. 105, no. 3, pp. 838-847, 2007.

[40] C. S. Sung, C. H. Cherng, Z. H. Wen et al., "Minocycline and fluorocitrate suppress spinal nociceptive signaling in intrathecal IL- $1 \beta$-induced thermal hyperalgesic rats," Glia, vol. 60, no. 12, pp. 2004-2017, 2012.

[41] W. Kleibeuker, E. Gabay, A. Kavalaars et al., "IL-1 $\beta$ signaling is required for mechanical allodynia induced by nerve injury and for the ensuing reduction in spinal cord neuronal GRK2," Brain, Behaviour and Immunity, vol. 22, no. 2, pp. 200-208, 2008.

[42] G. K. Hershey, M. F. Friedrich, L. A. Esswein, M. L. Thomas, and T. A. Chatila, "The association of atopy with a gain-offunction mutation in the alpha subunit of the interleukin-4 receptor," New England Journal of Medicine, vol. 337, no. 24, pp. 1720-1725, 1997.

[43] M. Wills-Karp and F. D. Finkelman, "Untangling the complex web of IL-4- and IL-13-mediated signalling pathways," Science Signaling, vol. 1, no. 51, p. pe55, 2008.

[44] F. Q. Cunha, S. Poole, B. B. Lorenzetti, F. H. Veiga, and S. H. Ferreira, "Cytokine-mediated inflammatory hyperalgesia limited by interleukin-4," British Journal of Pharmacology, vol. 126, no. 1, pp. 45-50, 1999.

[45] W. A. Verri Jr., T. M. Cunha, C. A. Parada, S. Poole, F. Q. Cunha, and S. H. Ferreira, "Hypernociceptive role of cytokines and chemokines: targets for analgesic drug development?," Pharmacology \& Therapeutics, vol. 112, no. 1, pp. 116-138, 2006. 
[46] T. S. Huber, G. S. Gaines, M. B. Welborn III, J. J. Rosenberg, J. M. Seeger, and L. L. Moldawer, "Anticytokine therapies for acute inflammation and the systemic inflammatory response syndrome: IL-10 and ischemia/reperfusion injury as a new paradigm," Shock, vol. 13, no. 6, pp. 425-434, 2000.

[47] R. Baron, A. Binder, and G. Wasner, "Neuropathic pain: diagnosis, pathophysiological mechanisms, and treatment," The Lancet Neurology, vol. 9, no. 8, pp. 807-819, 2010.

[48] M. Tsuda, Y. Kohro, T. Yano et al., "JAK-STAT3 pathway regulates spinal astrocyte proliferation and neuropathic pain maintenance in rats," Brain, vol. 134, no. 4, pp. 1127-1139, 2011.

[49] J. Molet, A. Mauborgne, M. Diallo et al., "Microglial Janus kinase/signal transduction and activator of transcription 3 pathway activity directly impacts astrocyte and spinal neuron characteristics," Journal of Neurochemistry, vol. 136, no. 1, pp. 133-147, 2016.

[50] C. Börner, M. Wöltje, V. Höllt, and J. Kraus, "STAT6 transcription factor binding sites with mismatches within the canonical $5^{\prime}$-TTC...GAA-3' motif involved in regulation of delta- and mu-opioid receptors," Journal of Neurochemistry, vol. 91, no. 6, pp. 1493-1500, 2004.

[51] J. Kraus, C. Börner, E. Giannini et al., "Regulation of muopioid receptor gene transcription by interleukin- 4 and influence of an allelic variation within a STAT6 transcription factor binding site," Journal of Biological Chemistry, vol. 276, no. 43, pp. 43901-43908, 2001.

[52] M. Busch-Dienstfertig, D. Labuz, T. Wolfram, N. N. Vogel, and C. Stein, "JAK-STAT1/3-induced expression of signal sequenceencoding proopiomelanocortin mRNA in lymphocytes reduces inflammatory pain in rats," Molecular Pain, vol. 8, p. 83, 2012.

[53] A. E. Panerai and P. Sacerdote, "Beta-endorphin in the immune system: a role at last?," Immunology Today, vol. 18, no. 7, pp. 317-319, 1997.

[54] C. Börner, S. Lanciotti, T. Koch, V. Höllt, and J. Kraus, “ $\mu$ opioid receptor agonist-selective regulation of interleukin-4 in T lymphocytes," Journal of Neuroimmunology, vol. 263, no. 1-2, pp. 35-42, 2013.

[55] M. L. Vale, J. B. Marques, C. A. Moreira et al., "Antinociceptive effects of interleukin- $4,-10$, and -13 on the writhing response in mice and zymosan-induced knee joint incapacitation in rats," Journal of Pharmacology and Experimental Therapeutics, vol. 304, no. 1, pp. 102-108, 2003.

[56] N. Ueyler, T. Topuzoğlu, P. Schiesser, S. Hahnenkamp, and C. Sommer, "IL-4 deficiency is associated with mechanical hypersensitivity in mice," PLoS One, vol. 6, no. 12, article e28205, 2011.

[57] J. F. Marcelletti, J. Ohara, and D. H. Katz, "Collagen-induced arthritis in mice. Relationship of collagen-specific and total IgE synthesis to disease," Journal of Immunology, vol. 147, no. 12, pp. 4185-4191, 1991.

[58] K. Shuai, "Regulation of cytokine signaling pathways by PIAS proteins," Cell Research, vol. 16, pp. 196-202, 2006.

[59] G. da Rocha Castelar Pinheiro, R. K. Khandker, R. Sato, A. Rose, and J. Piercy, "Impact of rheumatoid arthritis on quality of life, work productivity and resource utilisation: an observational, cross-sectional study in Brazil," Clinical and Experimental Rheumatology, vol. 31, no. 3, pp. 334-340, 2013.

[60] F. Atzeni, L. Boccassini, M. Di Franco et al., "Chronic widespread in spondyloarthritis," Reumatismo, vol. 66, no. 1 , pp. 28-32, 2014.

[61] American College of Rheumatology Pain Management Task Force, "Report of the American College of Rheumatology Pain Management Task Force," Arthritis Care \& Research, vol. 62, no. 5, pp. 590-599, 2010.
[62] N. Courvoisier, M. Dougados, A. Cantagrel et al., "Prognostic factors of 10-year radiographic outcome in early rheumatoid arthritis: a prospective study," Arthritis Research \& Therapy, vol. 10, no. 5, p. R106, 2008.

[63] S. Odegard, A. Finset, P. Mowinckel, T. K. Kvien, and T. Uhlig, "Pain and psychological health status over a 10-year period in patients with recent onset rheumatoid arthritis," Annals of the Rheumatic Disease, vol. 66, no. 9, pp. 1195-1201, 2007.

[64] T. Sokka, A. Kankainen, and P. Hannonen, "Scores for functional disability in patients with rheumatoid arthritis are correlated at higher levels with pain scores than with radiographic scores," Arthritis and Rheumatism, vol. 43, no. 2, pp. 386-389, 2000.

[65] P. Sarzi-Puttini, T. Fiorini, B. Panni, M. Turiel, M. Cazzola, and F. Atzeni, "Correlation of the score for subjective pain with physical disability, clinical, and radiographic scores in recent onset rheumatoid arthritis," BMC Musculoskeletal Disorders, vol. 3, p. 18, 2002.

[66] N. A. Khan, H. J. Spencer, E. Abda et al., "Determinants of discordance in patients' and physicians' rating of rheumatoid arthritis disease activity," Arthritis Care \& Research, vol. 64, no. 2, pp. 206-214, 2012.

[67] P. Studenic, H. Radner, J. S. Smolen, and D. Aletaha, "Discrepancies between patients and physicians in the perception of rheumatoid arthritis disease activity," Arthritis and Rheumatism, vol. 64, no. 9, pp. 2814-2823, 2012.

[68] Y. C. Lee, J. Cui, B. Lu et al., "Pain persists in DAS28 rheumatoid arthritis remission but not in ACR/EULAR remission: a longitudinal observational study," Arthritis Research \& Therapy, vol. 13, no. 3, p. R83, 2011.

[69] P. Sarzi-Puttini, F. Salaffi, M. Di Franco et al., "Pain in rheumatoid arthritis: a critical review," Reumatismo, vol. 66, no. 1, pp. 18-27, 2014.

[70] D. A. Walsh and D. F. McWilliams, "Pain in rheumatoid arthritis," Current Pain Headache Reports, vol. 16, no. 6, pp. 509-517, 2012.

[71] D. A. Walsh and D. F. McWilliams, "Mechanisms, impact and management of pain in rheumatoid arthritis," Nature Reviews Rheumatology, vol. 10, no. 10, pp. 581-592, 2014.

[72] V. I. Shubayev, K. Kato, and R. E. Myers, Translational Pain Research: from Mouse to Man, L. Kruger and A. R. Light, Eds., CRC Press, Boca Raton, FL, USA, 2010.

[73] F. M. Brennan and I. B. McInnes, "Evidence that cytokines play a role in rheumatoid arthritis," Journal of Clinical Investigation, vol. 118, no. 11, pp. 3537-3545, 2008.

[74] M. Scuri, L. Samsell, and G. Piedimonte, "The role of neurotrophins in inflammation and allergy," Inflammation \& Allergy-Drug Targets, vol. 9, no. 3, pp. 173-180, 2010.

[75] A. Antonelli, S. M. Ferrari, D. Giuggioli, E. Ferranini, C. Ferri, and P. Fallahi, "Chemokine (C-X-C motif) ligand (CXCL) 10 in autoimmune diseases," Autoimmunity Reviews, vol. 13, no. 3, pp. 272-280, 2014.

[76] R. A. Fava, N. J. Olsen, G. Spencer-Green et al., "Vascular permeability factor/endothelial growth factor (VPF/VEGF): accumulation and expression in human synovial fluids and rheumatoid synovial tissue," Journal of Experimental Medicine, vol. 180, no. 1, pp. 341-346, 1994.

[77] M. Meeus, S. Vervisch, L. S. De Clerck, G. Moorkens, G. Hans, and J. Nijs, "Central sensitization in patients with rheumatoid arthritis: a systematic literature review," Seminars in Arthritis and Rheumatism, vol. 41, no. 4, pp. 556-567, 2012.

[78] K. Toth, I. Barna, G. Nagy, K. Wellinger, G. Horvath, and T. Bender, "Synovial fluid $\beta$-endorphin level in avascular 
necrosis, rheumatoid arthritis, and osteoarthritis of the femoral head and knee. A controlled pilot study," Clinical Rheumatology, vol. 30, no. 4, pp. 537-540, 2011.

[79] C. W. Denko and C. J. Malemud, "Role of the growth hormone/insulin-like growth factor-1 paracrine axis in rheumatic diseases," Seminars in Arthritis and Rheumatism, vol. 35, no. 1, pp. 24-34, 2005.

[80] H. L. Wright, R. C. Bucknall, R. J. Moots, and S. W. Edwards, "Analysis of SF and plasma cytokines provides insights into the mechanisms of inflammatory arthritis and may predict response to therapy," Rheumatology, vol. 51, no. 3, pp. 451-459, 2012.

[81] Z. Z. Xu, L. Zhang, T. Liu et al., "Resolvins RvE1 and RvD1 attenuate inflammatory pain via central and peripheral actions," Nature Medicine, vol. 16, no. 5, pp. 592-597, 2010.

[82] M. Giera, A. Ioan-Facsinay, R. Toes et al., "Lipid and lipid mediator profiling of human synovial fluid in rheumatoid arthritis patients by means of LC-MS/MS," Biochimica et Biophysica Acta, vol. 1821, no. 11, pp. 1415-1424, 2012.

[83] K. Phillips and D. J. Clauw, "Central pain mechanisms in the rheumatic diseases: future directions," Arthritis and Rheumatism, vol. 65, no. 2, pp. 291-302, 2013.

[84] L. C. Pollard, F. Ibrahim, E. H. Choy, and D. L. Scott, "Pain thresholds in rheumatoid arthritis: the effect of tender point counts and disease duration," Journal of Rheumatology, vol. 39, no. 1, pp. 28-31, 2012.

[85] T. Hummel, C. Schiessl, J. Wendler, and G. Kobal, "Peripheral and central nervous changes in patients with rheumatoid arthritis in response to repetitive painful stimulation," International Journal of Psychophysiology, vol. 37, no. 2, pp. 177-183, 2000.

[86] H. van Middendorp and A. W. M. Evers, "The role of psychological factors in inflammatory rheumatic diseases: from burden to tailored treatment," Best Practice \& Research Clinical Rheumatology, vol. 30, no. 5, pp. 932-945, 2016.

[87] P. Schweinhardt, N. Kalk, K. Wartolowska, I. Chessell, P. Wordsworth, and I. Tracey, "Investigation into the neural correlates of emotional augmentation of clinical pain," NeuroImage, vol. 40, no. 2, pp. 759-766, 2008.

[88] A. K. Jones, Q. Liyi, V. V. Cunningham et al., "Endogenous opiate response to pain in rheumatoid arthritis and cortical and subcortical response to pain in normal volunteers using positron emission tomography," International Journal of Clinical Pharmacology Research, vol. 11, no. 6, pp. 261-266, 1991.

[89] R. R. Edwards, C. O. Bingham III, J. Bathon, and J. A. Haythornthwaite, "Catastrophizing and pain in arthritis, fibromyalgia, and other rheumatic diseases," Arthritis and Rheumatism, vol. 55, no. 2, pp. 325-332, 2006.

[90] D. L. Goldenberg, "The interface of pain and mood disturbances in the rheumatic diseases," Seminars in Arthritis Rheumatism, vol. 40, no. 1, pp. 15-31, 2010.

[91] R. R. Edwards, C. Cahalan, G. Mensing, M. Smith, and J. A. Haythornthwaite, "Pain, catastrophizing, and depression in the rheumatic diseases," Nature Reviews Rheumatology, vol. 7, no. 4, pp. 216-224, 2011.

[92] F. Wolfe and K. Michaud, "Predicting depression in rheumatoid arthritis: the signal importance of pain extent and fatigue, and comorbidity," Arthritis and Rheumatism, vol. 61, no. 5, pp. 667-673, 2009.

[93] J. Fifield, H. Tennen, S. Reisine, and J. McQuillan, "Depression and the long-term risk of pain, fatigue, and disability in patients with rheumatoid arthritis," Arthritis and Rheumatism, vol. 41, no. 10, pp. 1851-1857, 1998.
[94] I. Rupp, H. C. Boshuizen, H. J. Dinant, C. E. Jacobi, and G. A. van den Bos, "Disability and health-related quality of life among patients with rheumatoid arthritis: association with radiographic joint damage, disease activity, pain, and depressive symptoms," Scandinavian Journal of Rheumatology, vol. 35, no. 3, pp. 175-181, 2006.

[95] S. Urrows, G. Affleck, H. Tennen, and P. Higgins, "Unique clinical and psychological correlates of fibromyalgia tender points and joint tenderness in rheumatoid arthritis," Arthritis and Rheumatism, vol. 37, no. 10, pp. 1513-1520, 1994.

[96] P. Dharmshaktu, V. Tayal, and B. S. Kalra, "Efficacy of antidepressants as analgesics: a review," Journal of Clinical Pharmacology, vol. 52, no. 1, pp. 6-17, 2012.

[97] A. J. Zautra, M. C. Davis, J. W. Reich et al., "Comparison of cognitive behavioral and mindfulness meditation interventions on adaptation to rheumatoid arthritis for patients with and without history of recurrent depression," Journal of Consulting and Clinical Psychology, vol. 76, no. 3, pp. 408-421, 2008.

[98] F. Wolfe, "Fibromyalgianess," Arthritis and Rheumatism, vol. 61, no. 6, pp. 715-716, 2009.

[99] F. Wolfe, D. J. Clauw, M. A. Fitzcharles et al., "Fibromyalgia criteria and severity scales for clinical and epidemiological studies: a modification of the ACR preliminary diagnostic criteria for fibromyalgia," Journal of Rheumatology, vol. 38, no. 6, pp. 1113-1122, 2011.

[100] L. E. Kazis, R. F. Meenan, and J. J. Anderson, "Pain in the rheumatic diseases. Investigation of a key health status component," Arthritis and Rheumatism, vol. 26, no. 8, pp. 1017-1022, 1983.

[101] F. Salaffi, P. Sarzi-Puttini, and F. Atzeni, "How to measure chronic pain: new concepts," Best Practice \& Research Clinical Rheumatology, vol. 29, no. 1, pp. 164-186, 2015.

[102] F. Salaffi, P. Sarzi-Puttini, A. Ciapetti, and F. Atzeni, "Clinimetric evaluations of patients with chronic widespread pain," Best Practice \& Research Clinical Rheumatology, vol. 25, no. 2, pp. 249-270, 2011.

[103] F. Salaffi, P. Sarzi-Puttini, A. Ciapetti, and F. Atzeni, "Assessment instruments for patients with fibromyalgia: properties, applications and interpretation," Clinical and Experimental Rheumatology, vol. 27, no. 5, pp. S92-S105, 2009.

[104] T. Sokka, "Assessment of pain in patients with rheumatic diseases," in Pain Best Practice and Research Compendium, H. Breivik and M. Shipley, Eds., pp. 27-42, Elsevier, London, UK, 2007.

[105] C. S. Burckhardt, "The use of the McGill Pain Questionnaire in assessing arthritis pain," Pain, vol. 19, no. 3, pp. 305-314, 1984.

[106] R. Melzack, "The short-form McGill pain questionnaire," Pain, vol. 30, no. 2, pp. 191-197, 1987.

[107] C. S. Cleeland and K. M. Ryan, "Pain assessment: global use of the brief pain inventory," Annals Academy of Medicine Singapore, vol. 23, no. 2, pp. 129-138, 1994.

[108] R. D. Kerns, D. C. Turk, and T. E. Rudy, "The West HavenYale multidimensional pain inventory (WHYMPI)," Pain, vol. 23, no. 4, pp. 345-356, 1985.

[109] D. L. Anderson, "Development of an instrument to measure pain in rheumatoid arthritis: rheumatoid arthritis pain scale (RAPS)," Arthritis and Rheumatism, vol. 45, no. 4, pp. 317-323, 2001.

[110] S. Ahmed, T. Magan, M. Vargas, A. Harrison, and N. Sofat, "Use of the painDETECT tool in rheumatoid arthritis suggests neuropathic and sensitization components in pain reporting," Journal of Pain Research, vol. 7, pp. 579-588, 2014. 
[111] F. Salaffi, A. Ciapetti, M. Carotti, S. Gasparini, and M. Gutierrez, "Disease activity in psoriatic arthritis: comparison of the discriminative capacity and construct validity of six composite indices in a real world," BioMed Research International, vol. 2014, Article ID 528105, 12 pages, 2014.

[112] C. D. Lorish, N. Abraham, J. S. Austin, L. A. Bradley, and G. S. Alarcón, "A comparison of the full and short versions of the arthritis impact measurement scales," Arthritis Care \& Research, vol. 4, no. 4, pp. 168-173, 1991.

[113] R. F. Meenan, J. H. Mason, J. J. Anderson, A. A. Guccione, and L. E. Kazis, "AIMS2. The content and properties of a revised and expanded arthritis impact measurement scales health status questionnaire," Arthritis and Rheumatism, vol. 35, no. 1, pp. 1-10, 1992.

[114] J. E. Ware and C. D. Sherbourne, "The MOS 36-item shortform health survey (SF-36). I. Conceptual framework and item selection," Medical Care, vol. 30, no. 6, pp. 473-483, 1992.

[115] J. Brazier, N. Jones, and P. Kind, "Testing the validity of the Euroqol and comparing it with the SF-36 health survey questionnaire," Quality of Life Research, vol. 2, no. 3, pp. 169-180, 1993.

[116] F. Salaffi, M. Carotti, and W. Grassi, "Health-related quality of life in patients with hip or knee osteoarthritis: comparison of generic and disease-specific instruments," Clinical Rheumatology, vol. 24, no. 1, pp. 29-37, 2005.

[117] N. Bellamy, C. Wilson, and J. Hendrikz, "Population-based normative values for the Western Ontario and McMaster (WOMAC) osteoarthritis index: part I," Seminars in Arthritis and Rheumatism, vol. 41, no. 2, pp. 139-148, 2011.

[118] E. M. Roos, H. P. Roos, L. S. Lohmander, C. Ekdahl, and B. D. Beynnon, "Knee injury and osteoarthritis outcome score (KOOS)-development of a self-administered outcome measure," Journal of Orthopaedic and Sports Physical Therapy, vol. 28, no. 2, pp. 88-96, 1998.

[119] A. K. Nilsdotter, L. S. Lohmander, M. Klassbo, and E. M. Roos, "Hip disability and osteoarthritis outcome score (HOOS)-validity and responsiveness in total hip replacement," BMC Musculoskeletal Disorders, vol. 4, p. 10, 2003.

[120] I. K. Y. Lo, S. Griffin, and A. Kirkley, "The development of a disease-specific quality of life measurement tool for osteoarthritis of the shoulder: the Western Ontario Osteoarthritis of the shoulder (WOOS) index," Osteoarthritis and Cartilage, vol. 9, no. 8, pp. 771-778, 2001.

[121] R. Padua, L. Padua, E. Ceccarelli et al., "Italian version of the disability of the arm, shoulder and hand (DASH) questionnaire. Cross-cultural adaptation and validation," Journal of Hand Surgery, vol. 28, no. 2, pp. 179-186, 2003.

[122] R. M. Bennett, R. Friend, K. D. Jones, R. Ward, B. K. Han, and R. L. Ross, "The revised fibromyalgia impact questionnaire (FIQR): validation and psychometric properties," Arthritis Research \& Therapy, vol. 11, no. 4, p. R120, 2009.

[123] M. Di Carlo, A. Becciolini, V. Lato, C. Crotti, E. G. Favalli, and F. Salaffi, "The 12-item psoriatic arthritis impact of disease questionnaire: construct validity, reliability, and interpretability in a clinical setting," Journal of Rheumatology, vol. 44 , no. 3, pp. 279-285, 2017.

[124] A. Doria, S. Rinaldi, M. Ermani et al., "Health-related quality of life in Italian patients with systemic lupus erythematosus. II. Role of clinical, immunological and psychological determinants," Rheumatology, vol. 43, no. 12, pp. 1580-1586, 2004.
[125] Food and Drug Administration, Guidance for Industry, Patient-Reported Outcome Measures: Use in Medical Product Development to Support Labelling Claims, Food and Drug Administration, March 2017, http://www.fda.gov/downloads/ Drugs/Guidances/UCM193282.pdf.

[126] G. Demiris, L. B. Afrin, S. Speedie et al., "Patient-centered applications: use of information technology to promote disease management and wellness. A white paper by the AMIA knowledge in motion working group," Journal of the American Medical Informatics Association, vol. 15, no. 1, pp. 8-13, 2008.

[127] R. Roine, A. Ohinmaa, and D. Hailey, "Assessing telemedicine: a systematic review of the literature," Canadian Medical Association Journal, vol. 165, no. 6, pp. 765-771, 2001.

[128] A. Ranzolin, J. C. T. Brenol, M. Bredemeier et al., "Association of concomitant fibromyalgia with worse disease activity score in 28 joints, health assessment questionnaire, and short form 36 scores in patients with rheumatoid arthritis," Arthritis and Rheumatism, vol. 61, no. 6, pp. 794-800, 2009.

[129] L. C. Pollard, G. H. Kingsley, E. H. Choy, and D. L. Scott, "Fibromyalgic rheumatoid arthritis and disease assessment," Rheumatology, vol. 49, no. 5, pp. 924-948, 2010.

[130] E. Ton, M. F. Bakker, S. M. Verstappen et al., "Look beyond the disease activity score of 28 joints (DAS28): tender points influence the DAS28 in patients with rheumatoid arthritis," Journal of Rheumatology, vol. 39, no. 1, pp. 22-27, 2012.

[131] F. Wolfe, H. A. Smythe, M. B. Yunus et al., "The American college of rheumatology 1990 criteria for the classification of fibromyalgia. Report of the multicenter criteria committee," Arthritis and Rheumatism, vol. 33, no. 2, pp. 160-172, 1990.

[132] S. L. Whittle, A. N. Colebatch, R. Buchbinder et al., "Multinational evidence-based recommendations for pain management by pharmacotherapy in inflammatory arthritis: integrating systematic literature research and expert opinion of a broad panel of rheumatologists in the 3e initiative," Rheumatology, vol. 51, no. 8, pp. 1416-1425, 2012.

[133] S. L. Whittle, B. L. Richards, E. Husni, and R. Buchbinder, "Opioid therapy for treating rheumatoid arthritis pain," Cochrane Database of Systematic Reviews, vol. 11, Article ID CD003113, 2011.

[134] L. J. Crofford, "Adverse effects of chronic opioid therapy for chronic musculoskeletal pain," Nature Reviews Rheumatology, vol. 6, no. 4, pp. 191-197, 2010.

[135] B. L. Richards, S. L. Whittle, and R. Buchbinder, "Neuromodulators for pain management in rheumatoid arthritis," Cochrane Database of Systematic Reviews, vol. 1, Article ID CD008921, 2012.

[136] L. M. Arnold, D. L. Goldenberg, S. B. Stanford et al., "Gabapentin in the treatment of fibromyalgia: a randomized, double-blind, placebo-controlled, multicenter trial," Arthritis and Rheumatism, vol. 56, no. 4, pp. 1336-1344, 2007.

[137] L. J. Crofford, P. J. Mease, S. L. Simpson et al., "Fibromyalgia relapse evaluation and efficacy for durability of meaningful relief (FREEDOM): a 6-month, double-blind, placebocontrolled trial with pregabalin," Pain, vol. 136, no. 3, pp. 419-431, 2008.

[138] P. J. Mease, I. J. Russell, L. M. Arnold et al., "A randomized, double-blind, placebo-controlled, phase III trial of pregabalin in the treatment of patients with fibromyalgia," Journal of Rheumatology, vol. 35, no. 3, pp. 502-514, 2008.

[139] B. L. Richards, S. L. Whittle, and R. Buchbinder, "Antidepressants for pain management in rheumatoid arthritis," 
Cochrane Database of Systematic Reviews, vol. 11, Article ID CD008920, 2011.

[140] S. Ramiro, H. Radner, D. van der Heijde et al., "Combination therapy for pain management in inflammatory arthritis (rheumatoid arthritis, ankylosing spondylitis, psoriatic arthritis, other spondyloarthritis)," Cochrane Database of Systematic Reviews, vol. 10, Article ID CD008886, 2011.

[141] J. L. Marks, A. N. Colebatch, R. Buchbinder, and C. J. Edwards, "Pain management for rheumatoid arthritis and cardiovascular or renal comorbidity," Cochrane Database of Systematic Reviews, vol. 10, Article ID CD008952, 2011.

[142] H. Radner, S. Ramiro, R. Buchbinder, R. B. Landewe, D. van der Heijde, and D. Aletaha, "Pain management for inflammatory arthritis (rheumatoid arthritis, psoriatic arthritis, ankylosing spondylitis and other spondylarthritis) and gastrointestinal or liver comorbidity," Cochrane Database of Systematic Reviews, vol. 1, Article ID CD008951, 2012.

[143] S. H. Roth and G. Boost, "An open trial of naproxen in rheumatoid arthritis patients with significant esophageal, gastric, and duodenal lesions," Journal of Clinical Pharmacology, vol. 15, no. 4, pp. 378-384, 1975.

[144] L. Laine, S. P. Curtis, M. Langman et al., "Lower gastrointestinal events in a double-blind trial of the cyclo-oxygenase-2 selective inhibitor etoricoxib and the traditional nonsteroidal anti-inflammatory drug diclofenac," Gastroenterology, vol. 135, no. 5, pp. 1517-1525, 2008.

[145] F. K. Chan, A. Lanas, J. Scheiman, M. F. Berger, H. Nguyen, and J. L. Goldstein, "Celecoxib versus omeprazole and diclofenac in patients with osteoarthritis and rheumatoid arthritis (CONDOR): a randomised trial," The Lancet, vol. 376, no. 9736, pp. 173-179, 2010.

[146] A. N. Colebatch, J. L. Marks, and C. J. Edwards, "Safety of non-steroidal anti-inflammatory drugs, including aspirin and paracetamol (acetaminophen) in people receiving methotrexate for inflammatory arthritis (rheumatoid arthritis, ankylosing spondylitis, psoriatic arthritis, other spondyloarthritis)," Cochrane Database of Systematic Reviews, vol. 11, Article ID CD008872, 2011.

[147] National Collaborating Centre for Chronic Conditions (UK), Rheumatoid Arthritis: National Clinical Guidelines for Management and Treatment in Adults (NICE Clinical Guidelines, no. 79), Royal College of Physicians, London, UK, 2009, https://www.ncbi.nlm.nih.gov/books/NBK51812/.

[148] Y. Tizabi, L. L. Hurley, Z. Qualls, and L. Akinfiresoye, "Relevance of the anti-inflammatory properties of curcumin in neurodegenerative diseases and depression," Molecules, vol. 19, no. 12, pp. 20864-20879, 2014.

[149] A. L. Lopresti, S. D. Hood, and P. D. Drummond, "Multiple antidepressant potential modes of action of curcumin: a review of its antiinflammatory, monoaminergic, antioxidant, immune-modulating and neuroprotective effects," Journal of Psychopharmacology, vol. 26, no. 12, pp. 1512-1524, 2012.

[150] Y. Yang, X. Wu, Z. Wei et al., "Oral curcumin has antiarthritic efficacy through somatostatin generation via cAMP/PKA and $\mathrm{Ca}^{2+} / \mathrm{CaMKII}$ signaling pathways in the small intestine," Pharmacological Research, vol. 95-96, pp. 71-81, 2015.

[151] Y. Li, Y. Zhang, D. B. Liu, H. Y. Liu, W. G. Hou, and Y. S. Dong, "Curcumin attenuates diabetic neuropathic pain by downregulating TNF- $\alpha$ in a rat model," International Journal of Medical Sciences, vol. 10, no. 4, pp. 377-381, 2013.

[152] F. T. Ji, J. J. Liang, L. Liu, M. H. Cao, and F. Li, "Curcumin exerts antinociceptive effects by inhibiting the activation of astrocytes in spinal dorsal horn and the intracellular extracellular signal-regulated kinase signaling pathway in rat model of chronic constriction injury," Chinese Medical Journal, vol. 126, no. 6, pp. 1125-1131, 2013.

[153] EMA/CHMP/425279/2013, Committee for Medicinal Products for Human Use (CHMP). Xeljanz Assessment Report, February 2017, http://www.ema.europa.eu/docs/en_GB/ document_library/EPAR_-_Public_assessment_report/human/ 002542/WC500154697.pdf.

[154] G. G. Song, S. C. Bae, and Y. H. Lee, "Efficacy and safety of tofacitinib for active rheumatoid arthritis with an inadequate response to methotrexate or disease-modifying antirheumatic drugs: a meta-analysis of randomized controlled trials," Korean Journal of Internal Medicine, vol. 29, no. 5, pp. 656-663, 2014.

[155] S. Ramiro, C. Gaujoux-Viala, J. L. Nam et al., "Safety of synthetic and biological DMARDs: a systematic literature review informing the 2013 update of the EULAR recommendations for management of rheumatoid arthritis," Annals of the Rheumatic Diseases, vol. 73, no. 3, pp. 529-535, 2014.

[156] X. Zhang, F. Liang, X. Yin et al., "Tofacitinib for acute rheumatoid arthritis patients who have had an inadequate response to disease-modifying antirheumatic drug (DMARD): a systematic review and meta-analysis," Clinical Rheumatology, vol. 33, no. 2, pp. 165-173, 2014.

[157] E. Salgado, J. R. Maneiro, L. Carmona, and J. J. Gomez-Reino, "Safety profile of protein kinase inhibitors in rheumatoid arthritis: systematic review and meta-analysis," Annals of the Rheumatic Diseases, vol. 73, no. 5, pp. 871-882, 2014.

[158] A. Berhan, "Efficacy, safety and tolerability of tofacitinib in patients with an inadequate response to disease modifying anti-rheumatic drugs: a meta-analysis of randomized double-blind controlled studies," BMC Musculoskeletal Disorders, vol. 14, p. 332, 2013.

[159] Y. He, A. Y. Wong, E. W. Chan et al., "Efficacy and safety of tofacitinib in the treatment of rheumatoid arthritis: a systematic review and meta-analysis," BMC Musculoskeletal Disorders, vol. 14, p. 298, 2013.

[160] P. Kawalec, A. Mikrut, N. Wiśniewska, and A. Pilc, "The effectiveness of tofacitinib, a novel Janus kinase inhibitor, in the treatment of rheumatoid arthritis: a systematic review and meta-analysis," Clinical Rheumatology, vol. 32, no. 10, pp. 1415-1424, 2013.

[161] D. Vyas, K. M. O’Dell, J. L. Bandy, and E. G. Boyce, "Tofacitinib: the first Janus kinase (JAK) inhibitor for the treatment of rheumatoid arthritis," Annals of Pharmacotherapy, vol. 47, no. 11, pp. 1524-1531, 2013.

[162] K. M. O’Dell and A. E. Rummel, “Tofacitinib: a novel oral Janus kinase inhibitor for rheumatoid arthritis," Formulary, vol. 47, no. 10, pp. 350-358, 2012.

[163] J. H. Coombs, B. J. Bloom, F. C. Breedveld et al., "Improved pain, physical functioning and health status in patients with rheumatoid arthritis treated with CP-690,550, an orally active Janus kinase (JAK) inhibitor: results from a randomised, double-blind, placebo-controlled trial," Annals of the Rheumatic Diseases, vol. 69, no. 2, pp. 413-416, 2010.

[164] G. V. Wallenstein, K. S. Kanik, B. Wilkinson et al., "Effects of the oral Janus kinase inhibitor tofacitinib on patient-reported outcomes in patients with active rheumatoid arthritis: results of two Phase 2 randomised controlled trials," Clinical and Experimental Rheumatology, vol. 34, no. 3, pp. 430-442, 2016.

[165] E. G. Boyce, D. Vyas, E. L. Rogan, C. S. Valle-Oseguera, and K. M. O'Dell, "Impact of tofacitinib on patient outcomes in rheumatoid arthritis - review of clinical studies," Patient Related Outcome Measures, vol. 7, pp. 1-12, 2016. 
[166] J. M. Kremer, B. J. Bloom, F. C. Breedveld et al., "The safety and efficacy of a JAK inhibitor in patients with active rheumatoid arthritis: results of a double-blind, placebocontrolled phase IIa trial of three dosage levels of CP690,550 versus placebo," Arthritis and Rheumatism, vol. 60, no. 7, pp. 1895-1905, 2009.

[167] Y. Tanaka, M. Suzuki, H. Nakamura, S. Toyoizumi, S. H. Zwillich, and Tofacitinib Study Investigators, "Phase II study of tofacitinib (CP-690,550) combined with methotrexate in patients with rheumatoid arthritis and an inadequate response to methotrexate," Arthritis Care \& Research, vol. 63, no. 8, pp. 1150-1158, 2011.

[168] R. Fleischmann, M. Cutolo, M. C. Genovese et al., "A phase IIb dose-ranging study of the oral JAK inhibitor tofacitinib (CP-690,550) or adalimumab monotherapy versus placebo in patients with active rheumatoid arthritis with an inadequate response to disease-modifying antirheumatic drugs," Arthritis and Rheumatism, vol. 64, no. 3, pp. 617-629, 2012.

[169] J. M. Kremer, S. Cohen, B. E. Wilkinson et al., "A phase IIb dose-ranging study of the ORAL JAK inhibitor tofacitinib (CP-690,550) versus placebo in combination with background methotrexate in patients with active rheumatoid arthritis and an inadequate response to methotrexate alone," Arthritis and Rheumatism, vol. 64, no. 4, pp. 970-981, 2012.

[170] D. van der Heijde, Y. Tanaka, R. Fleischmann et al., "Tofacitinib (CP-690,550) in patients with rheumatoid arthritis receiving methotrexate: twelve-month data from a twenty-four-month phase III randomized radiographic study," Arthritis and Rheumatism, vol. 65, no. 3, pp. 559-570, 2013.

[171] E. B. Lee, R. Fleischmann, S. Hall et al., "Tofacitinib versus methotrexate in rheumatoid arthritis," New England Journal of Medicine, vol. 370, no. 25, pp. 2377-2386, 2014.

[172] J. S. Smolen, J. M. Kremer, C. L. Gaich et al., "Patientreported outcomes from a randomised phase III study of baricitinib in patients with rheumatoid arthritis and an inadequate response to biological agents (RA-BEACON)," Annals of the Rheumatic Diseases, vol. 76, no. 4, pp. 694-700, 2016.

[173] European Medicines Agency, "Summary of opinion for Olumiant," February 2017, http://www.ema.europa.eu/docs/ en_GB/document_library/Summary_of_opinion_-_Initial_ authorisation/human/004085/WC500218183.pdf.

[174] M. Dougados, D. van der Heijde, Y. C. Chen et al., "Baricitinib in patients with inadequate response or intolerance to conventional synthetic DMARDs: results from the RA-BUILD study," Annals of the Rheumatic Diseases, vol. 76, no. 1, pp. 88-95, 2017. 


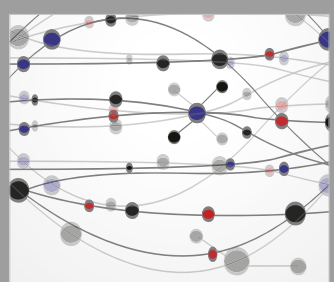

The Scientific World Journal
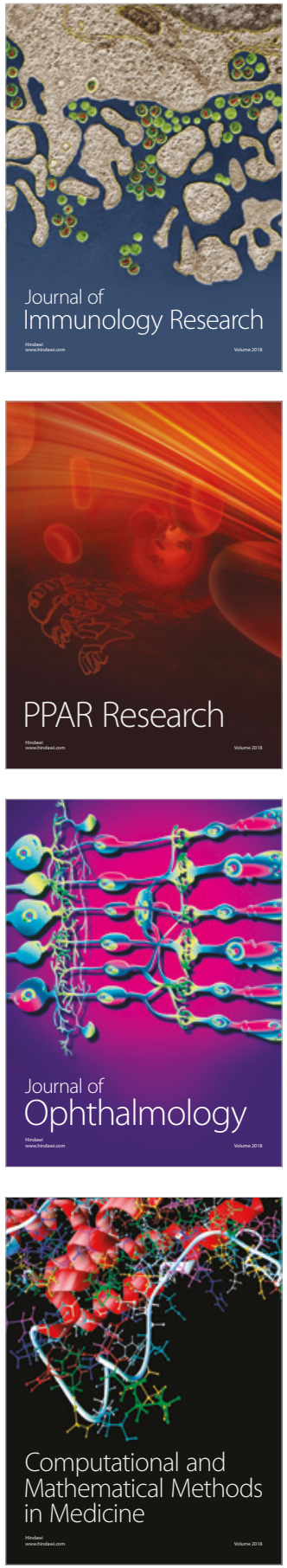

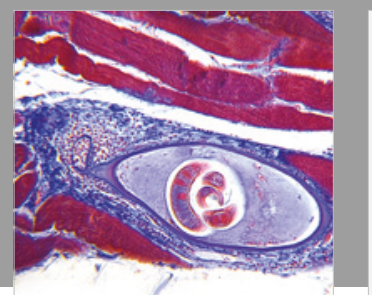

Gastroenterology Research and Practice

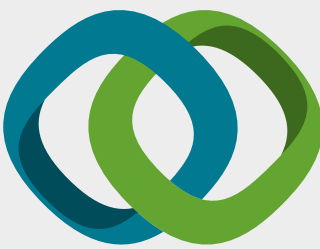

\section{Hindawi}

Submit your manuscripts at

www.hindawi.com
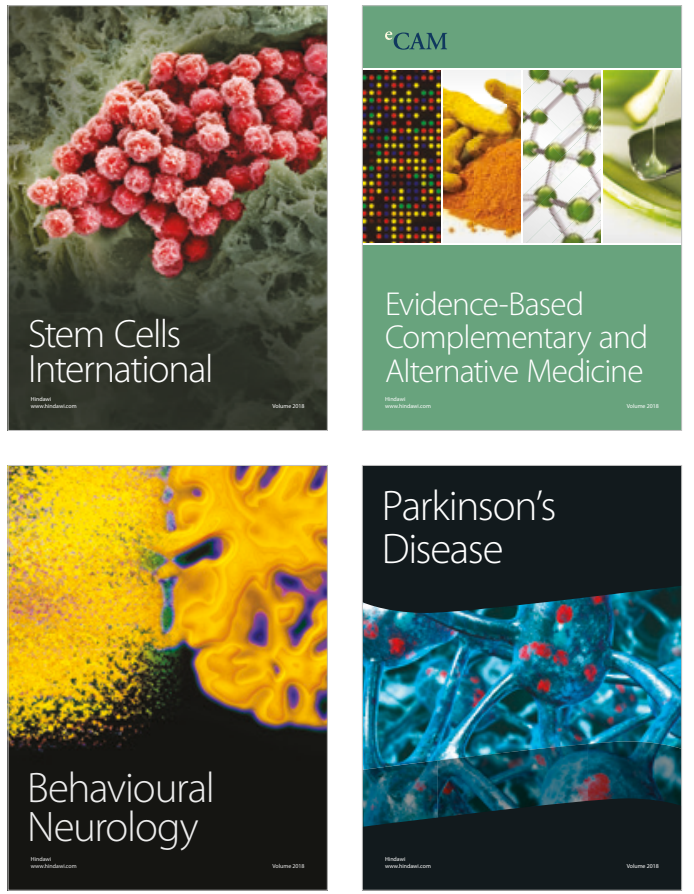

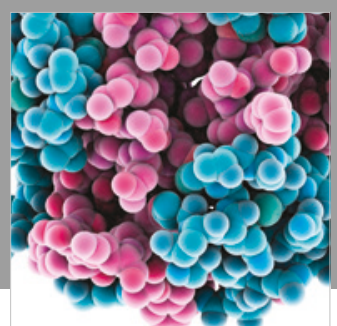

ournal of

Diabetes Research

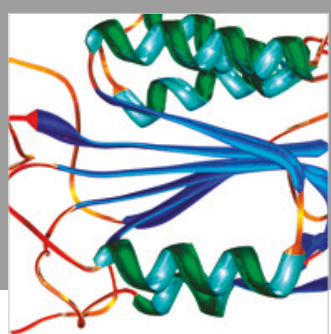

Disease Markers
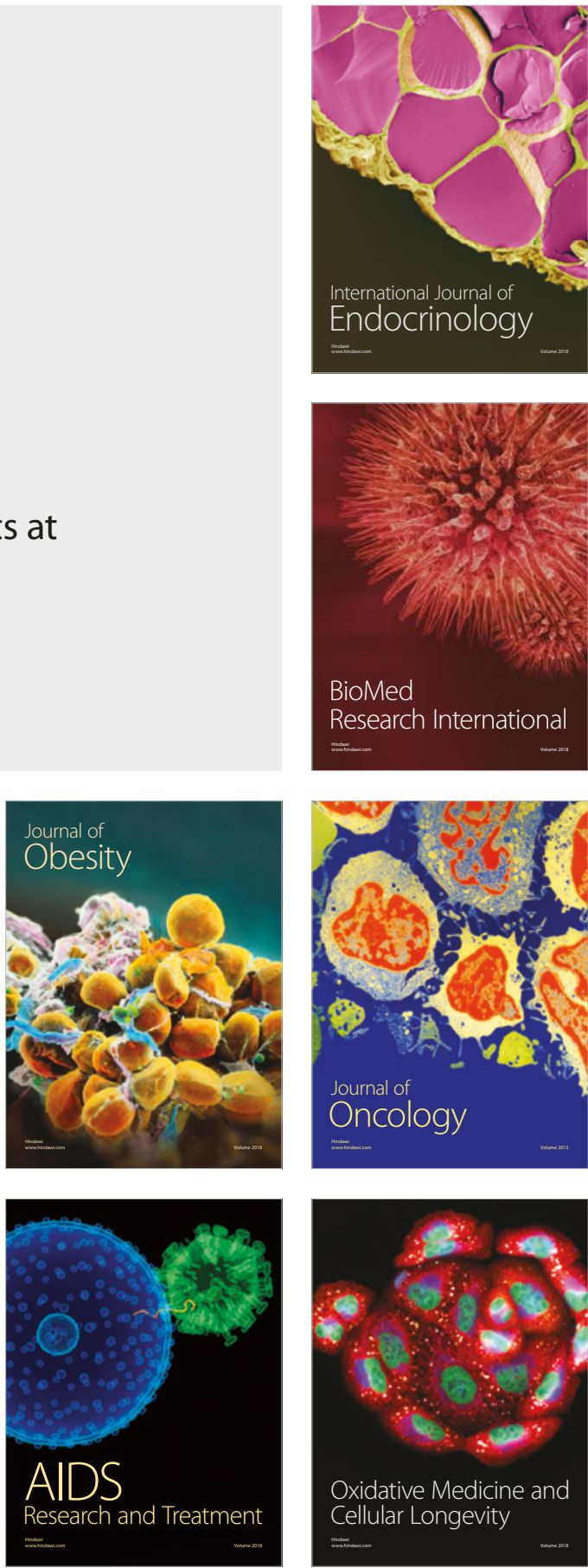